\title{
Animals and anomalies: An analysis of the UK veterinary profession and the relative lack of state reform
}

\section{Abstract}

The sociology of professions literature would predict that the contemporary state would not allow groups to continue unregulated or unreformed. However, this is indeed the case with the UK veterinary profession, with legislation dating back to 1966. Using an interdisciplinary analysis of published literature and reports, this paper assesses whether wider social, political and ethical dynamics can better explain this intriguing anomaly. We conclude with critical implications for the sociology of the professions. Furthermore, we argue that continuing to ignore the veterinary profession, and animals more generally, in sociological research will result in an impoverished and partial understanding of contemporary healthcare and occupations.

\section{Introduction: The sociology of the professions}

This paper adopts an interdisciplinary perspective to investigate the regulation of the veterinary profession in the UK. In essence, the paper tries to account for a strange anomaly: Why is it that this profession remains relatively unreformed, particularly in comparison to (human) healthcare? To answer this question we first turned to the social science literature on veterinarians and veterinary work.

Disappointingly, existing social science work on this issue is sparse. One explanation could be that this is symptomatic of a broader neglect of animals and 
human-animal relationships as research topics, more of which below. Nevertheless, there is an interesting stream of work on the dramatic feminisation of the profession (e.g. Irvine and Vermilya 2010), and increasing discussion of how veterinarians manage the ethics of their daily practice (e.g. Morris 2012). Lindsay Hamilton (2013), in this journal, has provided a useful summary of the studies that do exist, whilst also bemoaning a surprising lack of ethnographic work on the veterinary profession - surprising because, as she rightly argues, this area has relevance for the broader study of medical work. Hamilton provides a fascinating in-depth account of a farm animal practice and the importance of material objects in maintaining the prestige of the veterinarian in relation to administrative staff. However, her focus is undoubtedly at the micro level whereas our aim is to consider the broader social forces which may impact on, or be influenced by, the veterinary profession.

Given the lack of existing social scientific work on the regulation of veterinarians, we therefore decided to consider the sociology of the professions literature, to see if this could predict, or account for, the relative lack of recent veterinary regulation. The field has analysed, inter alia, how professions achieved a 'market shelter' (Freidson 1994, Timmermans 2008) by persuading states of the merits of according them this privilege, and on how professions develop 'professional projects' (Larson 1977) which seek to extend or defend the status and scope of the profession.

The state, and the professions (or aspirant professions) have thus been the main foci for this field. In the modern world, only the state can license professions. De Vries, Dingwall and Orfali (2009) categorise analyses of this relationship as either 'demand' or supply' theories. Demand theorists such as Larson (1977) focus on the aspirant profession, seeking state approval and a degree of protection from labour market competition through control over training or wages. Supply theorists such 2 
as Freidson (2001) place more of an emphasis on the role of the state in creating professions which suit the purposes of the state. In either case, the state is a central actor. By their very nature, professions, once established, have always sought independence from the state so far as they can, using a rhetoric of selfregulation. Some have achieved this successfully; Freidson (2001) characterises the 1950 s and 1960 s as a golden age for medicine in the USA.

Abbott (1988) builds on the analysis of theorists like Freidson and Larson but also stresses the role of other competing occupational and professional groups. For Abbott, professions need to carve out a distinctive jurisdiction, which enables them to distinguish themselves from their competitors, and defence of this jurisdiction is an ongoing project.

More contemporary approaches to the study of the professions have increasingly emphasised the role of the state. Freidson (2001) showed how the neo-liberal state has sought to extend its control over the professions, particularly medicine, in the time Freidson had been studying it (Freidson 1970). Freidson cautions against analysing this process in a simplistic way, arguing that sections of the medical profession have been co-opted by the state in order to facilitate its dominance, and that a kind of governmentality (Foucault 1991) is at work. This process can be seen clearly in recent changes to the regulation of medicine, which we will use as an exemplar. In the UK, the General Medical Council (GMC) no longer has a majority of doctors, with a substantial proportion of its membership now being health service managers, and UK doctors are now required to revalidate their medical qualifications on a regular basis. Analogous 'reforms' have been imposed on all the other health care professions in the UK. The state has used the rhetoric of public protection in order to justify this, aided in no small part by the scandals in UK 
health care in recent years (Bristol Royal Infirmary Inquiry 2001, Shipman Inquiry 2004, Mid Staffordshire NHS Foundation Trust Inquiry 2010).

The state's attempts to exercise greater control over the professions can be attributed to a variety of causes. Since the 1970s, states have faced rapidly rising costs in the provision of public services, and as staff are the most significant cost in the service sector, exercising greater control over professionals is seen as a way of controlling costs. Thus there has been a general attempt by states in the developed world to reduce the professional freedom and self-regulatory powers of the professions. Indeed, Evetts (2003:410) argues that the willingness of states to concede powers to professions is 'now almost universally in question'. This is particularly noticeable with, though not confined to, medicine, which we have used as an analytical focus.

In order to illustrate how extensive 'reform' of the health care professions has been in the UK, and how, by contrast, veterinary medicine remains relatively untouched, we will now focus on changes in the relationship between the most powerful of the health care professions, medicine, and the state. Medicine is also, as we shall see, the conscious (or unconscious) model that veterinary medicine often looks to in terms of professional regulation. Formal state regulation of medicine in the UK begins with the Medical Act of 1858 which establishes the GMC as the regulator. For the rest of the nineteenth and much of the twentieth centuries the state was content, via the GMC, to let the medical profession largely regulate itself. The establishment of the NHS in 1948 did not materially alter this arrangement. In fact, the state devolved to medicine the main managerial responsibility for the NHS, in return for doctors managing the contentious issue of resourcing health care. However, from the 1980 s onwards, medicine was subjected to a raft of direct legislation. including The Medical Act 1983 (Amendment) Order 2002; The Medical 
Act 1983 (Amendment) and Miscellaneous Amendments Order 2006; The Health Care and Associated Professions (Miscellaneous Amendments) Order 2008; The Medical Professions (Miscellaneous Amendments) Order 2008; The Health and Social Care Act 2008; The General and Specialist Medical Practice (Education, Training and Qualifications) Order 2010.

So how should we understand these changes since the 1980s? A persuasive explanation is that as part of the Thatcher/Reagan era of neo-liberalism, states began to attack what they saw as 'vested interests' in a wide variety of sectors, including health care. The 'New Public Management' (Hood 1991) was the manifestation of this in the public sector where a rhetoric of accountability, transparency and consumer choice was used by states (including the UK) to 'reform' public services along more market-oriented, 'business-like' lines. In the 'reforms' of health care in the UK, a quasi-market was seen as a way of controlling costs. Medicine, though one of the powerful and autonomous parts of the UK public sector, was no exception to this.

Much of the change was concerned with reducing the power of medicine within the NHS, which is not the main focus of this paper. In terms of regulation, the GMC itself was substantially changed from being a body dominated by medical practitioners to one where there is now a majority of lay members, appointed by the Secretary of State for Health. An overarching 'super-regulator' (the Commission for Healthcare Regulatory Excellence) for all the health care professional regulatory bodies was created, to which the GMC now reports (NHS Reform and Healthcare Professions Act 2002). The Medical (Professional Performance) Act 1995 had specifically charged the GMC with regulating poor performance by doctors, rather 
than just considering issues of professional misconduct. Compulsory revalidation for doctors was implemented in 2012.

In summary, the UK medical profession has been subjected to increasing state dominance. We now turn to consider the regulation of the UK veterinary profession to ascertain the extent to which this general trend is also applicable. This analysis is based on our critical reading of legal documents, websites, and through searches of the veterinary press. The article then moves to provide a social scientific analysis as to why this particular profession has been left relatively 'unreformed'. Whilst we attempt to apply insights from the sociology of the professions, we show that other streams of literature are necessary to make sense of the veterinary case. In seeking to broaden the explanatory focus for professions our aim has some parallels with that of Goodrick and Reay (2011), though we do not adopt their theoretical framework of 'institutional logics'.

The state and the UK veterinary profession

There are around 24,000 veterinarians in the UK making it a small, though not insignificant, profession (RCVS 2013a). This compares with 198,000 doctors registered by the GMC (GMC 2012). Veterinarians mainly work in private practice on a fee-for-service basis and veterinary partnerships are typically small organisations, though there is a growing number of larger corporate providers of veterinary services. As well as their work diagnosing and treating individual animals, farm animal veterinarians also have a public health role. Thirty years ago, many were employed directly by the government. This has now shifted as the work of the State Veterinary Service has been routed out to other agencies (Rowe 2009:6). Some veterinarians still do work on behalf of state agencies, principally 
the Animal Health and Veterinary Laboratories Agency, which is under the remit of the Department for Environment, Food and Rural Affairs (DEFRA).

Veterinary medicine was one of the first professions after human medicine to be formally recognised by the state, with the passing of the Veterinary Surgeons Act in 1881. Though the Royal College of Veterinary Surgeons (RCVS) had existed since 1844, the profession did not achieve occupational closure (Witz 1990) until the passing of the 1881 Act. After this, only practitioners registered with RCVS could call themselves, or practice as, veterinarians. Veterinarians working today operate under the 1966 Veterinary Surgeons Act which defines 'the art and science of veterinary surgery and medicine' as including:

'a. the diagnosis of diseases in, and injuries to, animals including tests performed on animals for diagnostic purposes;

b. the giving of advice based upon such diagnosis;

c. the medical or surgical treatment of animals; and

d. the performance of surgical operations on animals.'

The RCVS validates academic qualifications in the eight universities in the UK that offer courses leading to qualification as a veterinarian. Occupational closure in veterinary medicine continues to this day, to a degree that is probably the envy of other professions in terms of market shelter (Freidson 1994). The only conceivable competitor, veterinary nursing, is also under the control of the RCVS (via a 'regulator' administered by the RCVS), with a substantial number of members who are veterinarians, rather than being comprised solely of veterinary nurses and lay members, as other comparable professional bodies are. 
The RCVS council (governing body) comprises 42 members, nominated by the profession and the UK Vet Schools. Its membership is dominated by veterinarians, together with a small number of lay members (currently 9) (RCVS 2013b). The RCVS, though principally a regulator, also has a role in representing the profession more generally, and in education and research. This could be regarded by some as a conflict of interest: Indeed, in the case of pharmacy the UK state was sufficiently concerned that a similar body (The Royal Pharmaceutical Society of Great Britain) had been split into two in the most recent 'reforms' of professional regulation in health care. The RPSGB was divested of its regulatory powers in 2010, and a new General Pharmaceutical Council was established. This was because the Department of Health felt there was a conflict of interest between the RPSGB acting as the professional body (in terms of training and representing the profession), and acting as a regulator. The RPSGB was, at the time, the only regulator, apart from the RCVS, who had this dual role.

What is striking, then, is that recent regulatory reforms in the health care professions have not been extended to veterinary surgeons. In fact, the regulatory position in the UK for veterinarians is almost the opposite of that for the other professions. Whilst recent legislation does undoubtedly impact on veterinarians and their work (for example the Animal Welfare Act 2006; Dangerous Dogs Act 1991, Hunting Act 2004), there is no wholesale revision of the legislation which regulates the profession. The 1966 VSA therefore remains the most recent pertinent legislation.

Having said this, things have not remained static and some parts of the profession have been pressing for more formal reform of the 1966 Act. In 2008 the RCVS was asked to present a case for revision to a parliamentary select committee. Several reforms were proposed, including compulsory professional updating, and standards 8 
for practice, analogous with those enacted by the GMC, as well as a change to the profession's disciplinary processes. At the same time, the RCVS sought to tighten regulation of other groups involved in animal health, notably practitioners of alternative and complementary therapies which are growing in popularity with the owners of animals. This can be seen as an example of a conventional defence by a profession of its jurisdiction (Abbott 1988).

Despite the support of legislators (House of Commons Environment, Food and Rural Affairs Committee 2008), DEFRA, the government department responsible for regulation of veterinarians, were unenthusiastic about undertaking any reform of the 1966 Act, citing 'lack of Parliamentary time' for new legislation to be discussed. However, given that UK governments have de facto control of the Parliamentary timetable, this can be interpreted as a euphemism for reform being considered a Iow priority by DEFRA. There remains the sense of a rhetorical blame game about why this particular attempt at reform failed, with a subsequent Commons Select Committee report claiming that DEFRA left plans 'in a mess' but also arguing that the veterinary profession needs to 'iron out its differences' on what the aims of new legislation should be (cited in Vet Record, 2009:669).

Whilst wholesale reform has not occurred, more minor changes have recently been enacted. The government passed a Legislative Reform Order in January 2013 which in effect amends the VSA. This affects the RCVS in such a way that members of their disciplinary committees are now not made up of members of the RCVS council. The RCVS claims that this 'will provide regulation in line with modern practice, by ensuring that the same group of people is not responsible for setting the rules, investigating complaints and adjudication' and helps to 'address the single biggest deficit of the VSA' (RCVS 2013b). Likewise, the British Veterinary Association, the main professional association for veterinarians, considers that the 9 
current situation is adequate (BVA 2013). Despite this apparent consensus, the demand for more wholesale reform has not gone away (e.g. Vet Record 2013). Indeed, this was acknowledged by DEFRA even during their consultation on the aforementioned Legislative Reform Order, whilst still insisting that the government 'believes that self regulation by the veterinary profession remains the best solution' (DEFRA 2012: 5-6).

In summary, the veterinary profession presents a very interesting example which, despite serious debate, has not been subject to the levels of state reform that might have been predicted and that have been seen in the human medical field. This is just one reason why the profession is ripe for social scientific analysis. However, as is the case with the theme of non-human animals more generally (Hobson-West, 2007; Peggs 2013), sociologists have been slow to consider the veterinary profession and regulation. One important exception is Marie Fox who has written on animal law and has recently argued that 'the Veterinary Surgeons Act 1966 is no longer fit for purpose'. Fox accepts that there are practical and economic barriers to reform but is still highly critical and warns that the 'profession should heed the lessons of human medicine and take the initiative in promoting legislative change' (Fox 2012:245). This issue will be returned to in the conclusion, but for now, what is pertinent to note is that Fox's article does not make the question of why central. Stepping back from details about parliamentary time or this or that amendment, we therefore need to ask: why is it that veterinary medicine appears to be generally exempt from the wider project of the UK state to extend its control over the professions?

Accounting for the relative lack of regulation of the veterinary profession 
One possible place to start would be to explore the notion of profession itself, and to argue about whether or not veterinary medicine is best understood as such. Interestingly, veterinary medicine is briefly mentioned in Etzoni's (1969) classical text on the semi-professions. In the chapter entitled 'The theoretical limits of professionalization', William J Goode predicts that, for veterinary medicine, full professionalization will not happen and that 'very likely the society will continue to decide that the stakes are not high enough in this case' (1969:296, emphasis added). Rather than rehashing older debates about what is and is not a profession (e.g. Parsons 1939), this paper will take a different route by exploring possible reasons for the apparent 'low stakes' involved in veterinary medicine. By drawing on a range of documents and literatures, we offer three interrelated explanations (1) The declining role of farming in the UK economy (a socio-economic factor); (2) the lack of an NHS for animals (a socio-political factor); and (3) the low moral status of animals (a socio-ethical factor). Understanding these factors should provide critical insight into why it is that the veterinary profession remains relatively 'unreformed' vis-a-vis human medicine.

\section{1) The decline of farming in the UK: Decoupling animals and public health}

In her compelling sociological account, 'Animals, Disease and Human Society', Swabe (1999) investigates the rise of veterinary medicine. She argues that since the earliest domestication of animals, sick animals have threatened the safety of human food supply and human health more generally through the transfer of disease. The development of veterinary schools in the late $18^{\text {th }}$ century was one modern response and meat inspection became an additional niche for veterinarians. By the $20^{\text {th }}$ century, veterinarians were recognised as having a state mandate for the prevention of animal disease and an important role in public health. 
Since then, various social and economic changes have affected the veterinary profession. As argued by Swabe (1999), the actual risks to humans from animals have reduced, in large part due to advances in medical fields such as parasitology, immunology and microbiology. If animals are seen as less important in terms of human health risk, then this arguably reduces the perceived public health role of the veterinary profession. In addition, the past hundred years has seen dramatic changes in the relative economic importance of agriculture. According to a UK farming charity, the last twenty years or so have seen further significant decline on several measures including GDP contribution, total farming income, and the size of the farming workforce (Living Countryside 2013).

This shifting social and economic reality has impacted on (and been influenced) by the veterinary profession. Indeed, Swabe's account brings home the dramatic shift, from a mere hundred years ago when dogs and cats were 'more or less shunned by the veterinary profession' (Swabe,1999:180) in favour of horses, to the current situation, where small animal work now accounts for around $70 \%$ of a veterinarian's time (RCVS 2011). In other words, the intensification of agriculture and increasing pet ownership has led to a professional shift, from a focus on large animals with farmers as clients, to a focus on small companion animals with the general public as clients.

So what is the political impact of this? Some authors have argued that this equates to a lessening of vets' social mandate to protect human health (Morris 2009), given the key historical link between livestock and human and disease described above. Indeed, Everitt (2011: 62) has interpreted this as evidence that the link between the veterinary profession and the State has weakened. Indeed, her view would seem to find support in a recent high profile report on food animal production which argued that the 'secular decline in the relative standing of farming and food animal 12 
veterinary practice' is putting the relationship between government and the veterinary profession under 'increasing strain' (Rowe 2009: 6-11).

Whilst not disputing the importance of these historical shifts and contemporary tensions, we would argue that other factors can be identified which represent a counterpoint to some of these trends. For example, recent outbreaks of swine and avian flu have reconfirmed the importance of animals as potential threats to public health. Whilst some of the disease outbreaks may not have caused devastation in human populations, social science work has commented on the high social cost in terms of fear and stigma (e.g. Eichelberger 2007). The economic costs should also not be underestimated. In a recent review, Narrod et al (2012) cites statistics claiming that in the past 60 years, zoonotic pathogens are responsible for $65 \%$ of disease events. In the last 10 years alone, the World Bank estimates the direct cost of zoonotic disease is over $\$ 20$ billion, with indirect costs estimated at $\$ 200$ billion. This increased focus on the relationship between human and animal health is one aspect of what has become known as the One Health perspective to which, some have argued, social scientists should be much more actively contributing (Rock et al, 2009).

Furthermore, veterinarians' shift from care of farm to companion animals in the home does not necessarily remove the question of human health. As Swabe reminds us (1999), humans can catch disease from their companion animals. Veterinarians therefore still play a role in the prevention of disease. More radically, if we flip the discussion from consideration of animals causing disease to their role in promoting health, there is increasing interest in the role of companion animals in helping their owners to remain healthy and suffer fewer illness events. There is debate in the medical literature about why this seems to be the case, and whether animal ownership creates health gains directly (possibly through animals acting as 13 
social support), indirectly (through encouraging interaction with other people), or whether a co-factor (such as socioeconomic status) is at play (McNicholas, 2005). Regardless of which view you take, it remains the case that companion animal ownership has the potential to improve human health, with one estimate putting the saving to the NHS in the UK at $£ 1$ billion per year (BBC 1999). If veterinarians are the professional guardians of animal health then, viewed holistically, they (arguably) remain guardians of human health.

To summarise this section, the relative declining economic importance of livestock production and the associated shift to companion animal veterinary medicine could partly account for a perception by the state that the veterinary profession itself has less economic importance which in turn results in a perceived lack of need for state regulation. However, we have started to outline some potential challenges to this assumption. Either way, what we have discussed so far only provides a partial lens into this complex issue.

\section{2) The lack of a Nationalised Health Service for animals}

The UK state is centrally involved in the delivery of human health care, through the NHS, for which the vast majority of health care professionals work. The need to control the high and rising costs of health care, especially when funded directly out of taxation, and the continuing high political profile of health, mean that close control of the NHS, and the staff who work in it, is viewed as essential by the UK state. This partly explains the enthusiasm for regulation of the medical profession discussed above. 
By contrast, vets do not generally work for state bureaucracies (Evetts 2011), or the large international professional service firms (Von Nordenflycht 2010) increasingly characteristic of accountancy and the law. Whilst there is no NHS for animals, it is interesting to note in passing that some in government did suggest a Nationalised Veterinary Service in the 1960s, although plans never materialised (Rowe 2099:73). Without this overarching structure, regulation is therefore practically much harder to achieve. The result is that veterinary services operate as a localised market, with animal owners having considerable choice over where to go for treatment. As Morris (2009) argues, following Freidson, vets are an example of a profession who, to keep their clients, 'must give them what they want or someone else will' (Freidson 1970: 92). This could include actions such as euthanasia which is not medically warranted but is the will of the client. As neatly summarised by Morris, 'the veterinarian's role can feel at times closer to an auto mechanic rather than the medical practitioner in which the veterinarian must negotiate the type of services they can provide and perhaps even haggle over the cost of services, something physicians rarely do' (Morris, 2009:38). The issue of money is clearly key here since, 'in order to become more fully 'professionalized', occupational groups need to clearly distinguish their work from a business model' (Morris 2009:39). In the veterinary world, the relationship remains privatised between veterinarian and client, on a fee-for service, rather than third party payer basis, so that the state has less of an obvious role.

More important, perhaps, is the absence in veterinary medicine of the high profile scandals in the NHS so that the state has not had the political pretext for reform. As argued graphically in a letter to the Vet Times, 'Sometimes I almost wish we were regulated by the Department of Health rather than the Department of Endless Footling and Ridiculous Activities [DEFRA]. At least the Department of Health, based on the pretext of preventing the reincarnation of one of the rare medical 15 
assassins...has radically reordered the regulation of healthcare professions.' (Michell 2008:24). In short, we have not yet seen the veterinary equivalent of Harold Shipman, the notorious doctor who killed over 250 of his patients (Shipman Inquiry 2004).

However, it is possible to argue that there have in fact been high profile crises in agriculture which relate, directly or indirectly, to the veterinary profession. The UK outbreak of foot and mouth disease in 2001 had a huge social and cultural impact (Doring and Nerlich, 2009) which cost the public sector $£ 3$ billion directly, with an estimated further $£ 5$ billion in costs to the wider economy (ESRC 2004). Other examples include BSE and, more recently, the scandal across Europe of horse meat being passed off as beef or beef products. In terms of the latter it is interesting to note that the individual veterinarian present at meat slaughter in the UK used to be employed by the state; they are now supplied by a private firm under contract (Lawrence, The Guardian 2013). There are also 'scandals' that can be identified involving companion animals. Examples include the issue of pedigree dog breeding, and the poor animal treatment at a large veterinary chain, both of which were the subject of BBC television exposes (BBC 2008: BBC 2010) To be clear, it is not our intention to imply that the veterinary profession is, or should be, held accountable for these food, health and welfare issues. Rather, our purpose here is to argue that, had it wished, the state could have used the momentum created by these issues as a pretext for professional reform, as it did with human medicine.

In summary, the lack of an NHS for animals means that the state has had fewer opportunities for reform of the veterinary profession. Unlike in the human case where control of health is part of a neo-liberal financial control agenda (see Moran and Wood 1992), the cost of veterinary services has been left to the market. The state therefore arguably has less interest in getting involved. However, we have 16 
started to question the assumption that lack of reform can be explained by an absence of crises. What has been the 'elephant in the room' throughout our argument so far has been the socio-ethical standing of the animals themselves. Is their relatively low moral standing a reason for the state to concentrate their reform agenda elsewhere?

\section{3) The lower moral status of animals and animal health}

Whilst sociological interest in the relationship between humans and animals is relatively recent, the moral status of humans versus animals is a fundamental and long standing question in moral philosophy (Hobson-West 2007). The current 'moral orthodoxy' is that animals do have some moral status by virtue of their sentiency (their capacity to suffer). However, according to this view animals still have an inferior moral status because they lack personhood. The meaning of personhood is complex and disputed, but is generally held to relate to a variety of cognitive abilities such as rationality, intelligence, creativity, language use, beliefs and preferences, and self consciousness (see Garner, 2005:45-47). As Peggs (2013) has recently argued in this journal, sociology itself has also absorbed the assumption that animals are morally inferior.

In practice this supposed lower moral status has allowed animals to be used instrumentally by humans as transport or as sources of food. Animals were thus traditionally regarded as a business asset, so that the main task for the veterinarian was to minimise cost to the client and help them maximise profitability (Fettman and Rollin 2002:1386). This helps explain the impression, summarised by Carbone (2004:117) that 'to many people, veterinary medicine is much closer to agriculture and to dog shows than to human medicine. It is animal medicine, not animal 
medicine'. This association with animals, Morris (2009:34), argues, makes veterinary practice an example of Hughes' (1958) 'dirty work'. To quote a frustrated US veterinarian cited in Morris' later book, 'Sometimes people don't even know we are real doctors. We worked just as hard as doctors for just as long, but people think, because our patients are animals, that we don't deserve the same respect' (Morris 2012:177).

This background helps account for Goode's assertion back in 1969 that whatever they do in practice, veterinary surgeons cannot cause as much harm as a doctor. Goode (1969:269) argues that 'The claim to autonomy or trust loses its point unless the client or society can in fact be harmed because of unethical or incompetent work by the practitioner.' Indeed, Moline (1986) has argued that veterinarians are not professionals in the same sense as doctors because trust is less crucial. According to this view, animals cannot be embarrassed by information held about them. If animals have a lower moral status and less capacity to be 'harmed' (by a breach of trust), then this, partly, explains a lack of urgency on the part of the state for regulation of the profession.

Having said all this, we would like to destabilise the long-term robustness of the claims made in this section. Indeed, different branches of social science are currently engaged in muddying these very waters. For example, social theorists have argued that in a postmodern state of flux, the position of animals has changed from that just described to a situation where animals 'become substitute love objects and companions precisely because they can be involved in enduring relations of mutual dependency' (Franklin 1999:57). This potentially disrupts the old boundary between human and animal in terms of who/what is considered part 
of intimate personal relationships (for more detail see Hobson-West 2007). The result is arguably an 'improvement' in the moral and social status of animals. By contrast, scholars working in the field known as critical animal studies (for an example see Taylor and Twine, 2014) seek to highlight the continuation of social and institutional systems of animal exploitation. Overall, then, this potential shift in, or at least problematisation of, the moral status of animals can also be linked to contemporary developments in veterinary medicine. As discussed above, we have seen a dramatic shift from rural large animal veterinary work to urban companion animal work. If owners (note the language of property still remains) increasingly see their animals as part of the family and small animal work is primarily what veterinarians do, then arguably the social status of the animal on the consulting table blurs from property into patient. Pets therefore have an intrinsic or emotional, rather than financial, value such that 'considerations for informed consent [are] not unlike those for parent, child and paediatrician' (Fettman \& Rollin 2002:1386, and see Coombes 2005). As in human medicine, questions of confidentiality do also come into play: Client confidentiality is one of the five key principles of the RCVS Code of Conduct (RCVS 2012). In short, therefore, it is too simplistic to rely on Goode's argument that the veterinary profession cannot 'do harm'.

This is not to say that animals are now seen as equivalent to humans or that there is one defined view on the moral status of animals within the veterinary profession (Morgan \& McDonald 2007). Rather, what we are highlighting is a situation of potential flux in human-animal relations and an interrelated change in the role of the veterinarian. If our analysis is correct and animals are increasingly considered as patients, then veterinarians can in fact do considerable harm, both to the animals themselves and to their human 'owner'. This raises the stakes, in Goode's terms, of the profession of veterinary medicine, and makes the failure for the state 
to increase regulation of the veterinary profession even more surprising. Perhaps the state has just not kept pace with the changing social and ethical landscape.

\section{Conclusion}

This article started with the sociology of the professions and our observation that the state has been, and remains, a central unit of analysis. We outlined why and how the UK state has continued to expand its control of medicine, though these processes have extended to other professions, particularly in health care, as well. Taking this body of work seriously, we would have expected to see increasing state regulation of the veterinary profession. However, having analysed the current regulatory framework we found that the state has left this particular profession relatively unreformed, despite recent minor changes. Our aim in this paper was to use the literature to explore potential reasons why this remains the case. Using an interdisciplinary approach, three possible factors were identified.

We argued that the decline of agriculture in the UK, the lack of NHS for animals, and the relatively lower moral status of animals are all potential reasons for the apparent lack of state interest. However, we also questioned these accounts. The impact of zoonoses and the link between pet ownership and human health act as potential counterbalances to the declining role of agriculture, such that the veterinarian arguably remains a key player in the protection of human health. Whilst the lack of NHS for animals is significant, we also questioned the claim that the state does not have the pretext for reform. And finally, we started to destabilise the often unacknowledged assumption that animals have lower moral standing. This opens up the possibility that humans (and animals) can be significantly harmed, and thus removes one of the objections to treating veterinarians in the same vein 
as human healthcare professionals. In short, the current political accommodation around the regulation of the veterinary profession may not hold.

Our analysis shows that the UK veterinary profession is at a pivotal moment in its history and appears caught in a complex bind. The role of veterinarian is rapidly changing whilst their regulation, minor changes notwithstanding, dates back to 1966. Some may find evidence of the profession advocating for reform as surprising. However, one explanation for this is that the elite of the profession see the situation in human healthcare as a harbinger of what might come their way. Indeed, Fox (2012:255) has warned that 'The worst case scenario would be for the profession to resist change, only to have it forced upon it in the wake of a scandal such as those which ultimately prompted changes to the regulation of the medical profession'. Another explanation is that regulation is itself one of the ways in which existing professional boundaries are delineated and policed. For example, it may be that others in the private sector - such as vaccine manufacturers, feed or insurance companies - are seen by the state as increasingly important social actors in the animal/human health domain. Whether this is perceived as an encroachment on the profession would be one interesting area for further empirical research. Such work could also contribute to the wider literature on regulation theory, and the question of which non-state actors 'compensate', if the state is perceived to be weak or absent (see Grabosky 2013).

For the sociology of professions more generally, our contribution is to direct the attention of scholars to look wider than a focus on the professions, their competitors and the state, for all that it is analytically essential. What we have shown in this paper is that broader social, economic and political factors can play a major (and sometimes crucial) role in determining relations between professions and states. This explains the anomalous status of veterinary medicine vis-à-vis the 
state, by comparison with the human health professions. Modern states are pursuing a wide range of agenda, and professions may not be the main focus of their attention in any given setting, or time. Indeed, it would be instructive to carry out further research internationally, to assess the extent to which the arguments about the role of veterinarians stand up in countries with less of a contemporary history of centralised healthcare, or in developing countries where agriculture and the ownership of 'working animals' may be less evidently in decline.

And finally, this article functions as an example of how a critical interdisciplinary lens can be turned towards a relatively un-explored area of social life. As we have already noted, social science has historically ignored the position of animals, although this is being increasingly critiqued by those working in human-animal studies. Indeed, some authors in this burgeoning field have used the marginalisation of animals as an opportunity to question the entire project of sociology (Peggs 2013). From our perspective, one practical consequence may be an associated lack of analysis of the veterinary profession. For those scholars interested in health and medicine we contend that this dearth of research is particularly problematic. Just as medical science is increasingly recognising the need for a One Health agenda for human and animal health and disease (Rock et al 2009), so should social scientists embrace and promote what amounts to a One Social Science perspective. To continue to ignore veterinary medicine and the veterinary profession would therefore represent more than a failure to apply social scientific ideas to yet another empirical topic: Rather, it would represent a serious failure of imagination and result in an impoverished and partial understanding of contemporary health and healthcare.

\section{Acknowledgments}


The authors would like to thank colleagues at the University of Nottingham for their comments on drafts of this article. In particular, we appreciate the helpful suggestions of Alison Edgley, Vanessa Ashall, and Marnie Brennan. All errors remain the authors' own.

\section{References}

Abbott, A. (1988) The system of the professions: an essay in the expert division of labour, Chicago: University of Chicago Press.

Allsop, J. (2006) Medical Dominance in a Changing World: The UK Case, Health Sociology Review 15: 444-457.

BBC news (1999) Pets could save NHS $£ 1$ bn a year. Retrieved from http://news.bbc.co.uk/1/hi/health/441483.stm

BBC (2008) Panorama: Pedigree Dogs Exposed. BBC1 19 August 2008.

BBC (2010) Panorama Special: It Shouldn't Happen at a Vets. BBC1 22 July 2010

Bristol Royal Infirmary Inquiry (2001) Retrieved from http://www.bristolinquiry.org.uk/

British Veterinary Association (2013) Veterinary Surgeons Act. Retrieved from http://www.bva.co.uk/atoz/Veterinary Surgeons Act.aspx

Carbone, L. (2004). What Animals Want Oxford University Press: New York: 
Coombes, R. (2005) Do doctors and vets face similar ethical challenges? British Medical Journal, 331: 1227.

DEFRA (2012) Proposed Legislative Reform Order to amend the Veterinary Surgeons Act 1966 Retrieved from

http://www.defra.gov.uk/consult/2012/01/16/veterinary-surgeons-1201/

de Vries, R. Dingwall, R. \& Orfali, K. (2009) The Moral Organization of the Professions: Bioethics in the United States and France, Current Sociology 57:555579.

Doring, M., \& Nerlich, B. (eds) (2009) The Social and Cultural Impact of Foot and Mouth Disease in the UK in 2001: Experiences and Analyses. Manchester: Manchester University Press.

Eichelberger. L. (2007) SARS and New York's Chinatown: The politics of risk and blame during an epidemic of fear, Social Science \& Medicine, 68: 991-995.

ESRC (2004) ESRC Centre for Business Relationships, Accountability, Sustainability and Society. The UK Foot and Mouth Epidemic of 2001: A Research Resource. Retrieved from http://www.fmd.brass.cf.ac.uk/index.html

Etzioni, A. (1969) The semi-professions and their organization. New York: Free Press.

Everitt, S. (2011) Clinical decision making in veterinary practice. Unpublished PhD thesis, University of Nottingham. 
Evetts, J. (2003) The Sociological Analysis of Professionalism: Occupational Change in the Modern World, International Sociology 18:395-415.

Evetts, J. (2011) Sociological Analysis of Professionalism: Past, Present and Future. Comparative Sociology 10:1-37.

Fettman, M. and Rollin, B. (2002) 'Modern elements of informed consent for general veterinary practitioners.' Journal of the American Veterinary Medical Association 221(10): 1386-93.

Foucault, M. (1991) Governmentality. In G. Burchell, C. Gordon C and P. Miller (eds.) The Foucault Effect: Studies in Governmentality. Chicago: University of Chicago Press.

Fox, M. (2012) Veterinary Ethics and Law in C.M. Wathes et al (eds.), Veterinary \& Animal Ethics: Proceedings of the First International Conference on Veterinary and Animal Ethics, September 2011. Oxford: Blackwell.

Franklin, A. (1999) Animals and modern cultures. A sociology of human-animal relations in modernity, London: Sage. Freidson, E. (1970a) Profession of Medicine: A Study of the Sociology of Applied Knowledge, New York: Dodd, Mead \& Co. 
Freidson, E. (1970) Professional Dominance: The Social Structure of Medical Care, New York: Atherton \& Co.

Freidson, E. (1994) Professionalism Reborn: Theory, Prophecy and Policy, Cambridge: Polity Press.

Freidson, E. (2001) Professionalism: The Third Logic, Cambridge: Polity Press.

Garner, R. (2005) Animal Ethics, Cambridge: Polity.

GMC (2012) List of registered medical practitioners - statistics. Retrieved from http://www.gmc-uk.org/doctors/register/search_stats.asp

Goode, W.J. (1969) 'The theoretical limits of professionalization', in Etzioni, A (ed). The semi-professions and their organization. New York: Free Press:266-313.

Goodrick, E. \& Reay, T. (2011) Constellations of Institutional Logics: Changes in the Professional Work of Pharmacists, Work and Occupations 38, 372-416

Grabosky, P. (2013) Beyond responsive regulation: The expanding role of non-state actors in the regulatory process. Regulation and Governance, 7, 114-123.

Hamilton, L. (2013) The magic of mundane objects: culture, identity and power in a country vets' practice, The Sociological Review, 61:2:265-284. 
Hobson-West, P. (2007) Beasts and boundaries: An introduction to animals in sociology, science and society, Qualitative Sociology Review 3, 23-40.

Hood, C. (1991) A Public Management for All Seasons, Public Administration, 69: 319.

House of Commons Environment, Food and Rural Affairs Committee 2008 Veterinary Surgeons Act 1966 Sixth Report of Session 2007-08. (HC 348) London: The Stationery Office.

Hughes, E. C. (1958) Men and Their Work, Toronto, Canada: Collier-Macmillan.

Irvine, L., \& Vermilya, J. R. (2010). Gender work in a feminized profession: The case of veterinary medicine. Gender \& Society, $24,56-82$.

Larson M, F. (1977) The Rise of Professionalism: A Sociological Analysis, Burbank, CA: University of California Press

Lawrence, F. (2013) Horsemeat scandal: The essential guide. The Guardian, 15 February.

Living Countryside (2013) UK Agriculture. Retrieved from http://www.ukagriculture.com/farming today/economic trends.cfm

McNicholas, J. et al (2005) Pet ownership and human health: a brief review of evidence and issues, British Medical Journal, 331, 1252-1254. 
Michell, B. (2008) Is revision of our VSA an act of administrative gross indecency?, Veterinary Times, Nov 10, 24.

Mid Staffordshire NHS Foundation Trust Inquiry (2010) Retrieved from www.midstaffsinquiry.com

Moline, J.N. (1986) Professionals and professions: a philosophical examination of an ideal, Social Science and Medicine 22, 501-508.

Morgan, C. A., \& McDonald, M. (2007) Ethical dilemmas in veterinary medicine. Veterinary Clinics of North America: Small Animal Practice.37, 165-79.

Morris, P. (2009) Encounters with 'death work' in veterinary medicine: An ethnographic exploration of the medical practice of euthanasia. Unpublished PhD thesis, Northeastern University.

Morris, P. (2012) Blue Juice: Euthanasia in Veterinary Medicine. Temple University Press: Philadelphia.

Narrod., C., Zinsstag, J. \& Tiongco, M. (2012) A One Health Framework for estimating the economic costs of zoonotic diseases on society, EcoHealth 9, 150162.

Parsons, T. (1939) The professions and social structure, Social Forces 17, 457-67.

Peggs, K. (2013) The 'animal-advocacy agenda': exploring sociology for non-human animals. The Sociological Review, 61:3: 591-606. 
RCVS (2011) The 2010 RCVS Survey of the UK Veterinary and Veterinary Nursing Professions. Retrieved from http://www.rcvs.org.uk/document-library/rcvs-surveyof-the-veterinary-professions-2010/

RCVS (2012) Code of Professional Conduct for Veterinary Surgeons. Retrieved from https://www.rcvs.org.uk/advice-and-guidance/code-of-professional-conduct-forveterinary-surgeons/

RCVS (2013a) About the veterinary profession. Retrieved from http://www.rcvs.org.uk/about-us/about-the-veterinary-profession/

RCVS (2013b) New legislation updating RCVS disciplinary system finalised by Minister. Retrieved from http://www.rcvs.org.uk/news-and-events/news/newlegislation-updating-rcvs-disciplinary-system/

Rock, M., et al (2009) Animal-human connections 'one health' and the syndemic approach to prevention, Social Science and Medicine, 68, 991-995.

Rowe, P. (2009) Unlocking potential: A report on veterinary expertise in food animal production. Retrieved from http://archive.defra.gov.uk/foodfarm/policy/animalhealth/vservices/pdf/lowevets090806.pdf

Sandøe, P. \& Christiansen, S.B. (2008) Ethics of animal use, Oxford: Blackwell.

Shipman Inquiry (2004) Fifth Report - Safeguarding Patients: Lessons from the Past - Proposals for the Future. Command Paper Cm 6394. 
Swabe, J. (1999) Animals, disease and human society: Human-animal relations and the rise of veterinary medicine, London: Routledge.

Taylor, N. and Twine, R. eds. (2014) The Rise of Critical Animal Studies - From the Margins to the Centre. London: Routledge.

Timmermans, S. (2008) Professions and Their Work: Do Market Shelters Protect Professional Interests?, Work and Occupations 35, 164-188.

Vet Record (2009) Pragmatism and the act. 165, 669.

Vet Record (2013) One small step for regulation. Retrieved from http://veterinaryrecord.bmj.com/content/172/5/112.full.pdf+html

Von Nordenflycht, A. (2010) What is a professional service firm? Towards a theory and taxonomy of knowledge-intensive firms, Academy of Management Review, 35, $155-174$.

Witz, A. (1990) Patriarchy and Professions: The Gendered Politics of Occupational Closure, Sociology 24, 675-690. 